\title{
INJURIES TREATED AT A SPORTS INJURY CLINIC COMPARED WITH A NEIGHBOURING ACCIDENT AND EMERGENCY DEPARTMENT
}

\author{
S. ROWELL* and A. REES-JONES**
}

*Chelsea School of Human Movement, Brighton Polytechnic and **Medical Adviser, University of Sussex Sports Injury Clinic

\section{ABSTRACT}

Previous reports relating to sports injuries treated at hospital Accident and Emergency departments (A\&E) or Sports Injury Clinics (SIC) indicate differences between the groups. This study compared directly the sports injuries treated during overlapping time periods at an A\&E department $(n=2490)$ and a SIC $(n=340)$ set within the same geographical area. The two populations were found to differ significantly in age, sport, injury and injury site. Hospital patients tended to be younger, with an acute injury to the upper body or head which occurred during participation in sports where contact is likely. SIC patients tended to be older, with chronic or overuse injuries to the back or lower limb. It was found that there are significant differences between the sports injuries treated at the sports injury clinic and the hospital casualty department. It is concluded that demand is clearly shown for both types of treatment site when both are available in the same geographical area.

Key words: Sports injuries, Sports Injury Clinics, Accident and Emergency departments

\section{INTRODUCTION}

Attendance figures for sports injuries treated at a hospital Accident and Emergency (A\&E) department or a Sports Injury Clinic (SIC) are well documented. While Kingsbury (1978) looked at different sporting injury trends within hospital clinics located throughout the country, associated with either casualty, orthopaedic or rheumatology and rehabilitation departments, there are no published data which compare directly those treated at a hospital A\&E department and a SIC in the same geographical area. Such a comparison is important because it will demonstrate whether both types of medical service are used by the athletic population.

A general comparison of reported injury trends relating to athletes attending either a SIC or A\&E department seems to reveal a difference in the nature of the injuries seen at the two places of treatment.

The purpose of the present study was to compare the sports injuries treated during overlapping time periods at an A\&E department and a SIC situated in the same geographical area.

\section{METHOD}

All injuries ( $n=2868$ ) seen at the A\&E department of the Royal Sussex County Hospital, Brighton (RSCH) for the twelve month period following the installation of their computer system in October 1986 that were classified as 'sports injuries' by the hospital were analysed with regard to the patients' age, sex, location of injury, sport and injury diagnosis. Of the original 2868 injuries 378 were not included in the further analysis: in 32 cases, records were insufficient; 18 were reattendances for adjustment/resetting of plaster casts. The remaining 328 of this group were considered to be 'leisure injuries' as opposed to 'sports injuries', and included 197 injuries which occurred during the use of leisure pools, in particular water slides.

The remaining data $(n=2490)$ were then compared with information relating to the injuries seen at the University of Sussex Sports Injury Clinic (USSIC) over the 12 months of 1986 ( $n=340$ ). The USSIC is a self-referral clinic which operates two evenings per week, staffed by general practi-

Address for correspondence:

Miss S. Rowell

Chelsea School of Human Movement

Brighton Polytechnic

Brighton

Sussex tioners, physiotherapists and podiatrists. Analysis of the occupations of those attending the USSIC showed only $23 \%$ to be students: a similar figure to that obtained at other SICs (unpublished data).

The results were analysed using the two-sample t-test and the chi-square test on the SPSS- $X$ statistics package. Where a significant value for chi-squared was obtained adjusted standardised residuals (ASR) were used to establish which of the individual cells were significant. ASR are approximately normally distributed, with a mean of zero and a standard deviation of one, therefore any values greater than 1.96, the $5 \%$ standard normal deviate are, significant. Where the ASR is positive the observed frequency is greater than the expected frequency, where it is negative the observed frequency is less than the expected frequency.

\section{RESULTS}

2,490 sports injuries (to 2,478 individuals) treated at the $\mathrm{RSCH}$ and 340 (to 324 individuals) at the USSIC were analysed. Significant relationships were found in the following categories:

Age: Overall there was a significant difference in the ages of the patients seen at the two places of treatment (Table I). When individual sports were examined, significant age differences were observed in rugby, other team sports, racquet sports, running, cricket, outdoor pursuits and gym/dance. In all categories the average age of those seen at the hospital was lower.

Sex: There was was a slightly higher percentage of females treated at the USSIC than at the RSCH (Table II).

Site of injury: The place of treatment was found to be related to the anatomical site of injury (chi-square $=$ 385.98, $P<0.0001$ ). Analysis of the individual ASR values showed there was a greater incidence of injury to the head, chest and hand/wrist area being treated at the hospital, whilst injuries to the spine/back, upper leg and knee were seen more frequently at the SIC (Table III).

Type of injury: There was a significant link between the place of treatment and the injury diagnosis (chi-square = 807.57, $P<0.0001$ ). ASR showed there was a significant bias towards treatment at the A\&E for those suffering from concussion, contusion, open wounds or abrasions, dislocations and fractures. Tendon and ligament injuries, muscle tears and those conditions classified as 'overuse' were more frequently treated at the sports injury clinic (Table IV). 
TABLE I

Comparison of patient age differences at the two places of treatment

\begin{tabular}{|c|c|c|c|c|c|c|c|}
\hline \multirow[b]{2}{*}{ Sport } & \multicolumn{3}{|c|}{$\begin{array}{l}\text { Royal Sussex } \\
\text { County Hospital }\end{array}$} & \multicolumn{3}{|c|}{$\begin{array}{l}\text { University of Sussex } \\
\text { Sports Injury Clinic }\end{array}$} & \multirow{2}{*}{$\begin{array}{c}\text { Level of } \\
\text { significance }\end{array}$} \\
\hline & No. & Mean age & SD & No & Mean age & SD & \\
\hline $\begin{array}{l}\text { Overall Number } \\
\text { of patients }\end{array}$ & 2478 & 23.4 & 9.9 & 324 & 29.7 & 10.6 & $* * *$ \\
\hline Soccer & 863 & 22.8 & 8.4 & 67 & 23.8 & 6.9 & \\
\hline Rugby & 186 & 20.8 & 6.5 & 21 & 25.4 & 5.4 & * \\
\hline Racquet Sports & 156 & 29.9 & 11.9 & 58 & 36.3 & 11.2 & ** \\
\hline Other Team Sports & 172 & 20.4 & 8.3 & 29 & 25.5 & 6.8 & ** \\
\hline Running & 66 & 25.3 & 11.5 & 76 & 33.1 & 10.2 & $* * *$ \\
\hline Martial Arts & 81 & 23.7 & 8.2 & 21 & 25.3 & 5.3 & \\
\hline Outdoor Pursuits & 154 & 24.2 & 10.5 & 17 & 32.5 & 11.3 & * \\
\hline Gymnastics/Dance & 74 & 18.2 & 12.1 & 16 & 25.4 & 10.6 & * \\
\hline Wheels & 76 & 21.7 & 12.7 & 6 & 31.3 & 14.4 & \\
\hline Other Sports & 116 & 28.8 & 11.0 & 9 & 33.8 & 15.9 & \\
\hline Cricket & 88 & 27.3 & 10.5 & 4 & 45.7 & 11.3 & ** \\
\hline Sport/age unknown & 446 & & & & & & \\
\hline
\end{tabular}

* $=\mathrm{P}<0.05 \quad$ ** $=\mathrm{P}<0.001 \quad$ *** $\mathrm{P}=<0.0001$

Major sports within each category

Martial Arts: boxing, judo, karate, kung fu

Outdoor Pursuits: skiing, climbing, hill walking, sailing, windsurfing

Gymnastics/Dance: aerobics, folk dance, gymnastics, weight training

Wheels: motorbike, cycling, skateboarding

Other: golf, swimming, bowls, fishing

TABLE I

Male and female attendances at the two places of treatment

\begin{tabular}{lrrrrrr}
\hline & \multicolumn{2}{c}{ Overall } & \multicolumn{2}{c}{ Hospital } & \multicolumn{2}{c}{ Clinic } \\
& No. & $\%$ & No. & $\%$ & No. & $\%$ \\
\hline Male & 2164 & 82 & 1911 & 83 & 253 & 78 \\
Female & 461 & 18 & 390 & 17 & 71 & 22 \\
\hline
\end{tabular}

Total Chi-squared $=4.83, P<0.05$

(In 177 cases patients sex was not recorded)

TABLE III

Sites of injury at the two places of treatment

\begin{tabular}{lrrrrrrrr}
\hline & \multicolumn{9}{c}{ Hospital } & & Clinic & & $\begin{array}{c}\text { P value } \\
\text { significant } \\
\text { at 5\% }\end{array}$ \\
\hline Site & Total & \multicolumn{1}{c}{ No. } & $\%$ & ASR & No. & $\%$ & ASR & \\
\hline Head & 349 & 348 & 14.0 & +7.2 & 1 & 0.3 & -7.2 & $*$ \\
Spine and Neck & 118 & 72 & 2.9 & -9.2 & 46 & 13.5 & +9.2 & $*$ \\
Shoulder & 143 & 123 & 4.9 & -0.7 & 20 & 5.9 & +0.7 & \\
Arm & 120 & 109 & 4.4 & +1.0 & 11 & 3.2 & -1.0 & \\
Hand and Wrist & 543 & 538 & 21.6 & +8.8 & 5 & 1.5 & -8.8 & $*$ \\
Chest & 99 & 97 & 3.9 & +3.1 & 2 & 0.6 & -3.1 & $*$ \\
Upper Leg & 94 & 57 & 2.3 & -8.3 & 37 & 10.9 & +8.3 & $*$ \\
Knee & 387 & 272 & 10.9 & -11.5 & 115 & 33.8 & +11.5 & $*$ \\
Lower Leg & 169 & 147 & 5.9 & -0.4 & 22 & 6.5 & -0.4 & \\
Ankle & 536 & 478 & 19.2 & +0.9 & 58 & 17.1 & -0.9 & \\
Foot & 272 & 249 & 10.0 & +1.9 & 23 & 6.8 & -1.9 & \\
Total number & & & & & & & & \\
of injuries & & 2490 & & & 340 & & & \\
\hline
\end{tabular}

Total Chi-squared $=385.98, P<0.0001$

Degrees of Freedom $=10$
TABLE IV

Injury diagnosis at the two places of treatment

\begin{tabular}{|c|c|c|c|c|c|c|c|c|}
\hline \multirow[b]{2}{*}{ Diagnosis } & \multirow[b]{2}{*}{ Total } & \multicolumn{3}{|c|}{ Hospital } & \multicolumn{3}{|c|}{ Clinic } & \multirow{2}{*}{$\begin{array}{c}\text { P value } \\
\text { significant } \\
\text { at } 5 \%\end{array}$} \\
\hline & & No. & $\%$ & ASR & No. & $\%$ & ASR & \\
\hline Sprain or Strain & 983 & 860 & 34.5 & -0.6 & 123 & 36.2 & +0.6 & \\
\hline Concussion & 68 & 68 & 2.7 & +3.1 & 0 & 0.0 & -3.1 & $*$ \\
\hline Contusion & 548 & 534 & 21.4 & +7.6 & 14 & 4.1 & -7.6 & \\
\hline Open Wound & 295 & 295 & 11.8 & +6.7 & 0 & 0.0 & -6.7 & $*$ \\
\hline Fracture & 475 & 468 & 18.8 & +7.7 & 7 & 2.1 & -7.7 & * \\
\hline Dislocation & 63 & 61 & 2.4 & +2.2 & 2 & 0.6 & -2.2 & $*$ \\
\hline $\begin{array}{l}\text { Tendon and } \\
\text { Ligament }\end{array}$ & 68 & 17 & 0.7 & -16.2 & 51 & 15.0 & +16.2 & $*$ \\
\hline Unknown & 115 & 81 & 3.3 & -5.9 & 34 & 10.0 & +5.9 & $*$ \\
\hline Other & 159 & 92 & 3.7 & -12.0 & 67 & 19.7 & +12.0 & * \\
\hline Overuse & 34 & 14 & 0.6 & -8.4 & 20 & 5.9 & +8.4 & * \\
\hline Muscle Tear & 22 & 0 & 0.0 & -12.7 & 22 & 6.5 & +12.7 & * \\
\hline $\begin{array}{l}\text { Total number } \\
\text { of injuries }\end{array}$ & & 2490 & & & 340 & & & \\
\hline
\end{tabular}

Total Chi-squared $=807.57, P<0.0001$

Degrees of Freedom $=10$

Sport: The place of treatment was found to be related significantly to the injured athletes sport (chi-square = 404.89, $P<0.0001$ ). ASR showed there was a significant bias towards treatment at the USSIC for those suffering from injuries incurred during running, martial arts and racquet sports. Soccer and cricket injuries were treated more frequently at the $\mathrm{RSCH}$ (Table V).

TABLE V

Sports involved at the two places of treatment

\begin{tabular}{|c|c|c|c|c|c|c|c|c|}
\hline \multirow[b]{2}{*}{ Sport } & \multirow[b]{2}{*}{ Total } & \multicolumn{3}{|c|}{ Hospital } & \multicolumn{3}{|c|}{ Clinic } & \multirow{2}{*}{$\begin{array}{l}\text { P value } \\
\text { significant } \\
\text { at } 5 \%\end{array}$} \\
\hline & & No. & $\%$ & ASR & No. & $\%$ & ASR & \\
\hline Soccer & 937 & 865 & 34.7 & +5.0 & 72 & 21.2 & -5.0 & $*$ \\
\hline Rugby & 209 & 188 & 7.6 & +0.9 & 21 & 6.2 & -0.9 & \\
\hline Racquet Sports & 214 & 156 & 6.3 & -7.1 & 58 & 17.1 & +7.1 & * \\
\hline $\begin{array}{l}\text { Other Team } \\
\text { Sports }\end{array}$ & 203 & 173 & 6.9 & -1.3 & 30 & 8.8 & +1.3 & \\
\hline Running & 146 & 66 & 2.7 & +16.3 & 80 & 23.5 & -16.3 & * \\
\hline Martial Arts & 106 & 82 & 3.3 & -3.4 & 24 & 7.1 & +3.4 & $*$ \\
\hline $\begin{array}{l}\text { Outdoor } \\
\text { Pursuits }\end{array}$ & 171 & 154 & 6.2 & +0.9 & 17 & 5.0 & -0.9 & \\
\hline Gym/Dance & 92 & 74 & 3.0 & -2.3 & 18 & 5.3 & +2.3 & * \\
\hline Wheels & 84 & 78 & 3.1 & +1.4 & 6 & 1.8 & -1.4 & \\
\hline Cricket & 92 & 88 & 3.5 & +2.3 & 4 & 1.2 & -2.3 & $*$ \\
\hline Other & 130 & 120 & 4.8 & +1.6 & 10 & 2.9 & -1.6 & \\
\hline Unknown & 446 & 446 & 17.9 & +8.5 & 0 & 0.0 & -8.5 & * \\
\hline $\begin{array}{l}\text { Total number } \\
\text { of injuries }\end{array}$ & & 2490 & & & 340 & & & \\
\hline
\end{tabular}

Total Chi-squared $=404.89, P<0.0001$

Degrees of Freedom $=10$

\section{DISCUSSION}

The results obtained from the USSIC and the RSCH showed the same trends as observed in previous analyses of sports injuries treated at SICs (Devereaux and Lachmann, 1983; Ferry, 1985; McNaught-Davis and Thole, 1984; Dowey, 1984; Galasko et al, 1982) or hospital A\&E departments (Bedford and Macauley, 1984; Burke et al, 1983; Crompton 
and Tubbs, 1977; Watters et al, 1984). It can therefore be assumed that the populations attending the two treatment locations in Brighton provide a representative sample of those sports injuries seen at sports injury clinics and hospital casualty departments in the United Kingdom.

\section{Age}

The patients attending the USSIC were significantly older than those seen at the RSCH (mean 29.7 vs. 23.4). A similar age differential was also noted by Kingsbury (1978), who found that the patients treated at casualty-based clinics were younger than those seen at rehabilitation-based clinics. Bedford and Macauley (1984), Burke et al (1983) and Watters et al (1984) all found that over half the sportsrelated injuries treated in casualty departments were to those aged 21 or under.

\section{Sex}

Although small, the significantly greater percentage of females treated at the USSIC may suggest that women were less likely to be involved in sports where physical contact is likely. This is assuming that there was no bias in the 177 cases where sex was not recorded.

\section{Site of Injury}

Analysis of the relationship between the place of treatment and the injury location showed six categories to be significantly linked.

Head: Injuries to the head tended to be acute in nature and have potentially serious consequences. Such injuries are thus seen at the hospital.

Hand and wrist: Like those to the head, these injuries tended to be acute in nature. While they are unlikely to be as serious as injuries to the head, acute sprains, dislocations or fractures of this area require immediate hospital treatment.

Chest: These also tended to be acute, with a predominance of contusions $(57 \%)$ and thus tended to be treated at the hospital.

Spine and back: On first analysis the fact that this group had a higher attendance rate at the USSIC may seem surprising. A closer examination, however, showed the majority of these problems to be chronic disc or muscular injuries and not acute in nature.

Knee and Upper leg: Injuries to these areas were predominantly sprains or strains ( $40 \%$ of the total). The $\mathrm{RSCH}$ treated 45 contusion or open wounds while the USSC saw 67 tendon or other 'overuse' injuries.

Overall, the site of injury in relation to place of treatment closely followed those patterns previously noted in individual clinic analyses.

\section{Injury Diagnosis}

Injuries that were traumatic or acute in aetiology (therefore requiring immediate treatment, fractures, open wounds/ abrasions, dislocations and contusions) were treated far more frequently at the RSCH, where facilities are available 24 hours a day. All cases of concussion observed during the study were treated at the hospital. Injuries which were classified as tendon or ligament injuries, overuse or chronic muscle tears, while not so obviously disabling as the acute injuries seen at the hospital, can nevertheless inhibit or even prevent the athlete's normal sports participation, showed higher attendance rates at the USSIC, where staff are experienced in the treatment of chronic and overuse injuries.

The ASR value for the treatment of sprains and strains $( \pm 0.6)$ showed equal numbers were treated at the $A \& E$ and SIC (see Table IV). From the trends already established it is reasonable to assume that those sprains and strains treated at the hospital were acute: and that the more chronic ones treated at the SIC either had a more gradual onset, or were originally acute traumas which, through ineffective, inappropriate or non-treatment, had become chronic.

The attendance figures for injuries within the 'ill defined condition' (i.e. a precise diagnosis could not be made) and 'other' categories were higher for the USSIC than for the $\mathrm{RSCH}$. This could have been due to patients attending the clinic with long-term problems and/or as a 'last resort': $39.5 \%(128)$ of those treated at the USSIC had received prior treatment, $78(24 \%)$ from their own GPs.

\section{Sport}

Sport and injury diagnosis and position are linked. While the statistics showed certain sports were more frequently treated at either the hospital or the clinic, this was primarily a result of the nature of the injuries sustained. For example, those injured playing soccer had a higher incidence of acute lower limb injuries resulting from falls and tackles, as opposed to runners, who suffered predominantly from overuse injuries to the lower limbs.

In addition, although five of the sports groups showed no overall bias towards one particular place of treatment, closer analysis of these sports showed that the nature of the injuries incurred influenced where athletes sought treatment. For example the ASR value for rugby injuries (+ 0.9$)$ showed equal numbers to be treated at the hospital and the clinic. Seventy-two per cent (135) of the rugby injuries treated at the $A \& E$, however, were acute upper body injuries, compared to only $19 \%(4)$ of those treated at the SIC.

The 'Racquets' category showed nearly double the number of injuries being treated at the USSIC than would have been expected. This can be explained by the following:

(a) The Sussex University Sports Centre is a strong squash centre, used by the county teams, as well as fielding good league teams. Any minor acute or overuse injuries are likely to be seen at the SIC which is on campus.

(b) Examination of the 'Racquet' player injuries reveals that those with lower limb traumas (the majority) tended to suffer from chronic or overuse problems and were more likely to attend the USSIC; while those who had upper limb or head injuries, tended to require immediate treatment and attended the hospital, thus conforming to the established pattern for choice of place of treatment.

\section{CONCLUSION}

Analysis of sports injuries treated at a hospital casualty department and a sports injury clinic within the same geographical area revealed that the patients seen at the two treatment sites differed significantly in terms of age, sport played, injury diagnosis and site of injury.

In general, those seen at the hospital were likely to be younger and to have suffered an acute injury to the upper 
body or head, caused during participation in a sport where sudden contact is likely. Those attending the sports injury clinic tended to be older, suffering from chronic or overuse injuries to the back or lower limb, due to participation in sports of a typically less violent nature.

The results obtained from analysis of data collected at both treatment sites were in agreement with data previously pubished in the literature relating to attendance trends at casualty departments or at soft tissue sports injury clinics. Total support is therefore given to the statement “... sport injuries is not a narrow issue of a restricted group of people, but a broad community problem, it needs the basic structures of casualty, orthopaedic and rheumatology and rehabilitation clinics" (Kingsbury, 1978). These data show that, whilst hospitals provide for the treatment of acute sports injuries, there is also a need for treatment of chronic injuries. Where such treatment is available in the form of a specialised sports injury clinic, a clear demand is shown.

\section{ACKNOWLEDGEMENTS}

The authors would like to thank Mr. Perez-Avila and the medical staff at the Royal Sussex Hospital Accident and Emergency Department: Miss Jan Thole and the medical staff at the University of Sussex Sports Injury Clinic: Ms E. Colley, Brighton Polytechnic for help with the Statistics.

This study was supported by a grant from the Health Promotion Research Trust.

\section{References}

Bedford, P. and Macauley, B., 1984 "Attendances at a casualty department for sport-related injuries". Brit.J.Sports Med. 18: 116-121.

Burke, P., Buckley, N., McShane, D. and O'Conner, P., 1983 "Sports injuries and the casualty department". Irish Medical Journal 76: 127-128.

Crompton, B. and Tubbs, N., 1977 "A survey of sports injuries in Birmingham", Brit.J.Sports Med. 11: 12-15.

Devereaux, M. and Lachmann, S., 1983 "Athletes attending a sports injury clinic - a review". Brit.J.Sports Med. 17: 137-142.

Dowey, E., 1984 "Preliminary report - Sports injury clinic". Ulster Medical Journal 51: 88-92.

Ferry, D., 1985 "A survey of sports injuries in an NHS sports injuries clinic". Unpublished dissertation. University of Aberdeen.

Galasko, C., Menon, T. J., Lemon, G. L., Banks, A. J., Morris, M. A., Bourne, M. S. and Bentley, Y. S., 1982 "University of Manchester sports injury clinic". Brit.J.Sports Med. 16: 23-25.

Kingsbury, K., 1978 "The Sports Council pilot study of sport injury clinics". The Sports Council.

McNaught-Davis, J. P. and Thole, J., 1984 "University of Sussex Sports Injury Clinic: a report". Brit.J.of Phys.Ed. Jan. 26-27.

Watters, D., Brooks, S., Elton, R. A. and Little, K., 1984 "Sports injuries in an Accident and Emergency department". Arch. of Emergency Medicine 2: 105-112.

Title:

\title{
BOOK REVIEW
}

Authors:

A COLOUR ATLAS OF HUMAN ANATOMY. 2nd EDITION

Publisher:

\author{
R. M. H. McMinn and R. T. Hutchings
}

Wolfe Medical Publications, London, 1988

Price: $£ 29.50 \quad 358$ pages, numerous colour photos, $X$-rays Index

Cloth cover, Life size (also available in paper back, reduced size) ISBN 0723415269

This colour atlas is a most comprehensive and very clear series of photographs of dissections, as most of us would like to have done as students or anatomy demonstrators. It therefore shows the body as the anatomist would see it, the only thing missing being the smell of preservatives! In addition to the dissections, there are radiographs of the skeleton and of barium meals and swallows, the lungs, pyelograms and cholecystograms, and now the addition of ultrasound scans. The vessels of major organs and the bronchial tree are shown as photographs of the excellent resin casts in the Royal College of Surgeons made by the former prosector, Dr. D. H. Tompsett. The gelatin and dye injection specimens of the lungs, showing the broncho-pulmonary segments are well illustrated, and the corrosion casts of the heart and the coronary arteriograms are of special interest and clinical importance. One of the most dramatic figures is a corrosion cast of the veins of the neck, showing the enormous quantity of blood that they can hold, and makes one appreciate the vulnerability of these vessels to injury, and how easily they can be distended in heart failure.

It would have been tempting for the authors to use some of the photographs of specimens prepared for 'A Colour Atlas of Foot and Ankle Anatomy' by the same team and the same publisher, but I could only find one example where this had been done; all the other illustrations in this region appear to have been made from separate and meticulous dissections. A few errors in labelling have been allowed to pass final checking; the occipital region of the transverse section of the brain on page 70 is labelled "front" and the suprarenal vein on page 237 fig. B is labelled "suprarenal gland". As a graduate of the Newcastle-upon-Tyne School of Medicine, trained largely by disciples of Rutherford Morrison, I was glad to see the retention of "Morrison's Pouch", the hepato-renal pouch of peritoneum, and a few other eponyms are retained, the epiploic foramen "of Winslow", though the more common name of "Additus to the Lesser Sac" was omitted.

This book is NOT a dissecting manual with instructions of how to perform the exposure of any region, nor does it use drawings of regions with few exceptions, but it should prove a most valuable example of what one's dissection SHOULD show, and be most useful for revision, by student and post-graduate alike. Unfortunately I do not have access to the first edition, published in 1977 to make comparisons with the revised second edition, but the need to bring out other editions and not just reprints shows that human anatomy is a science that is still progressing, as new techniques are developed to explore hitherto inaccessible areas. 